\title{
Correction: Self-Administered Behavioral Skills-Based At-Home Virtual Reality Therapy for Chronic Low Back Pain: Protocol for a Randomized Controlled Trial
}

Laura M Garcia ${ }^{1,2}$, PhD; Beth D Darnall ${ }^{3}$, PhD; Parthasarathy Krishnamurthy ${ }^{4}$, MBA, PhD; Ian G Mackey ${ }^{1}$, BA; Josh Sackman $^{1}$, MBA; Robert G Louis ${ }^{5}$, MD; Todd Maddox ${ }^{1}$, PhD; Brandon J Birckhead ${ }^{6}$, MD, MHDS

${ }^{1}$ Research and Development, AppliedVR Inc, Los Angeles, CA, United States

${ }^{2}$ USC Creative Media and Behavioral Health Center, Los Angeles, CA, United States

${ }^{3}$ Department of Anesthesiology, Perioperative and Pain Medicine, Stanford University School of Medicine, Stanford, CA, United States

${ }^{4} \mathrm{C}$ T Bauer College of Business, Houston, TX, United States

${ }^{5}$ Division of Neurosurgery, Pickup Family Neurosciences Institute, Hoag Memorial Hospital, Newport Beach, CA, United States

${ }^{6}$ Division of Health Services Research, Department of Medicine, Cedars-Sinai Health System, Los Angeles, CA, United States

\section{Corresponding Author:}

Brandon J Birckhead, MD, MHDS

Division of Health Services Research

Department of Medicine

Cedars-Sinai Health System

Pacific Theaters Building, Suite 800116 N. Robertson Blvd.

Los Angeles, CA, 90048

United States

Phone: 18188500814

Email: bbirckhead@appliedvr.io

\section{Related Article:}

Correction of: https://www.researchprotocols.org/2021/1/e25291

(JMIR Res Protoc 2021;10(2):e27652) doi: 10.2196/27652

In "Self-Administered Behavioral Skills-Based At-Home Virtual Reality Therapy for Chronic Low Back Pain: Protocol for a Randomized Controlled Trial" (JMIR Res Protoc 2021;10(1):e25291), the authors noted five author names missing middle initials.

In the originally published paper, the list of authors appeared as follows:

Laura Garcia, Beth Darnall, Parthasarathy Krishnamurthy, Ian Mackey, Josh Sackman, Robert Louis, Todd Maddox, Brandon Birckhead
The list has been corrected as follows:

Laura M Garcia, Beth D Darnall, Parthasarathy Krishnamurthy, Ian G Mackey, Josh Sackman, Robert G Louis, Todd Maddox, Brandon J Birckhead

The correction will appear in the online version of the paper on the JMIR Publications website on February 12, 2021, together with the publication of this correction notice. Because this was made after submission to PubMed, PubMed Central, and other full-text repositories, the corrected article has also been resubmitted to those repositories.

This is a non-peer-reviewed article. Submitted 01.02.21; accepted 04.02.21; published 12.02.21.

Please cite as:

Garcia LM, Darnall BD, Krishnamurthy P, Mackey IG, Sackman J, Louis RG, Maddox T, Birckhead BJ

Correction: Self-Administered Behavioral Skills-Based At-Home Virtual Reality Therapy for Chronic Low Back Pain: Protocol for a

Randomized Controlled Trial

JMIR Res Protoc 2021;10(2):e27652

URL: http://www.researchprotocols.org/2021/2/e27652/

doi: $10.2196 / 27652$

PMID: 33577465 
CLaura M Garcia, Beth D Darnall, Parthasarathy Krishnamurthy, Ian G Mackey, Josh Sackman, Robert G Louis, Todd Maddox, Brandon J Birckhead. Originally published in JMIR Research Protocols (http://www.researchprotocols.org), 12.02.2021. This is an open-access article distributed under the terms of the Creative Commons Attribution License (https://creativecommons.org/licenses/by/4.0/), which permits unrestricted use, distribution, and reproduction in any medium, provided the original work, first published in JMIR Research Protocols, is properly cited. The complete bibliographic information, a link to the original publication on http://www.researchprotocols.org, as well as this copyright and license information must be included. 